\title{
Correction Fitness of Highly Skilled Combat Athletes by the Way of Using Methods of Training with Different Intervals
}

\author{
Epov O.G. \\ Research Institute of Sport \\ Russian State University of Physical Culture, Sport, Youth \\ and Tourism \\ Moscow, Russia
}

\author{
Kalinin E.M \\ Research Institute of Sport \\ Russian State University of Physical Culture, Sport, Youth \\ and Tourism \\ Moscow, Russia
}

\begin{abstract}
The success of competitive actions in striking kinds of combats from the point of view of physical training mostly depends on seed-power abilities and speed-power endurance, muscular groups, which directly take part in the process of battles. Arsenal of means and exercises from tactical and special training lets us successfully solve this task with optimum length and intensivity of performing the exercise, quantity of sets, runs, as well as rest intervals. For this purpose method of performing interval technical and tactical training was worked out - spurt with maximum intensivity.
\end{abstract}

Keywords — degree of training; exercise; length; training.

\section{INTRODUCTION}

While training the athletes of striking kinds of combats at the stage of immediate training to competitions tactical and special training has a big meaning. It is tactical and special training that is the main part of training process, physical training part goes to the middle ground. But what to do if it's necessary to solve a task to increase level of physical fitness?

One of the such variants is the increase of physical fitness by means of tactical and special training performing which all the groups of muscles are active that secure success in the competition activity with identical for battles power, speed, rate of muscle activity and also alike range of motion. That's why it's necessary to create such circumstances for doing exercises, which will lead to the change of athletes' physical fitness.

One of the most important criteria leading to decrease of numbers of strikes in the process of battles, sparrings or doing exercises is the increase of lactate concentration and as a result main muscles' exhaustion. They take part in motion activities. Decreased functioning is the main indicator of growing fatigue, however, while tense muscle activity exhaustion is first of all expressed in heavy subjective aspects, in decreased functioning of separate muscles and muscle elements by saving general working capacity at the same level that can be observed at the athletes of high qualification while working at the same power up to necessary refuse or in the competitive activity circumstances. Therefore, one may suggest (research supposal) that implementing tactical and special exercises of different length to the training process will be helpful to increase the physical fitness, increase of the results of competitive battles of taekwondo athletes of high qualification.

Enough attention is paid to this problem at the example of other kinds of combats $[1,2,3,5,7,9,10]$, and other kinds of sports $[6,8,11]$, while at the example of taekwondo the theme is not enough revealed $[4,12,13]$, that is a problem situation.

\section{RESEARCH MethodOlOGY}

For taking part in pedagogical process 2 highly qualified athletes were formed of striking kinds of combats taekwondo were divided into 2 groups of 10 athletes in each.

The first group - 10 athletes aged 19-22 years old were divided into 5 pairs. Period of taking lessons $8,6 \pm 1,2$ years, qualification candidate master -master of sports. This group of athletes did tactical and special exercises by interval method totally kit out according to the time limits of competitions in pairs. The tactical point is in gradual increase up to 3 , and then gradual decrease up to 1 , given to the each round of technical and tactical tasks, consisted of repeated attacks for number 1 and the length of the round $120 \mathrm{sec}$, according to the time limits of the round at competitions, 4 rounds were made. The interval between rounds is 1 minute. Contest of rounds:

The first round - number 1 makes an attack with a strike knocking down with the front leg with the strike dolio-chagi to the body hands of the opponent, then makes a takedown with the same leg dolio-chagi to the head, with the further leg makes the strike dolio-chagi to the body's open space. The second round - number 1 makes a takedown with the front leg opponent's block, with the same leg makes a takedown strike dolio-chagi to the body's open space. The third round - number 1 makes a closing in movement with a bounce of the front leg to the opponent then makes a takedown with a fist of a back hand jumock-chirugi to the body and strike dolio-chagi with the further leg to the head. 
The fourth round - number 1 makes a strike dvit-chagi with an obstacle to the opponent's body from the striking distance.

\section{Pairs change.}

The fifth number - number 2 makes an intention to attack the number 1 with the front leg a strike dolio-chagi to the body, number 1 makes a reciprocal attack with a strike miro-chagi with the nearest leg to body and the back leg makes a strike dvit-chagi to the body.

The sixth round - number 2 makes an intention to attack with a strike dolio-chagi to the body number 1 makes a reciprocal attack with a strike of back further arm jumockchirugi to the body, with the following strike dolio-chagi with the front leg to the head.

The seventh round- number 2 makes an attack with a strikeof further leg dolio-chagi to the body, number 1 makes a reciprocal attack with a strike dvit-chagi with the further leg to the body, with the following strike dolio-chagi with the front leg to the head. The eighth round - number 2 makes an attack with a strike dolio-chagi with the front leg to the body, number 1 makes the opponent's fall and meets him with the front leg strike to the body, with the following strike dolio-chagi to the head.

As a result each athlete during training lesson makes two series of active attack exercises and two series of defensive ones in turns. The length of the main part of training lesson$55 \mathrm{~min}$. There were planed three trainings in the week's microcycle: the first third and the fifth days. The content of the microcycle is represented in table I.

TABLE I. MICROCYCLE OF TRAINING BASED ON MAKING INTERVAL TECHNIC AND TACTIC EXERCISES DURING A

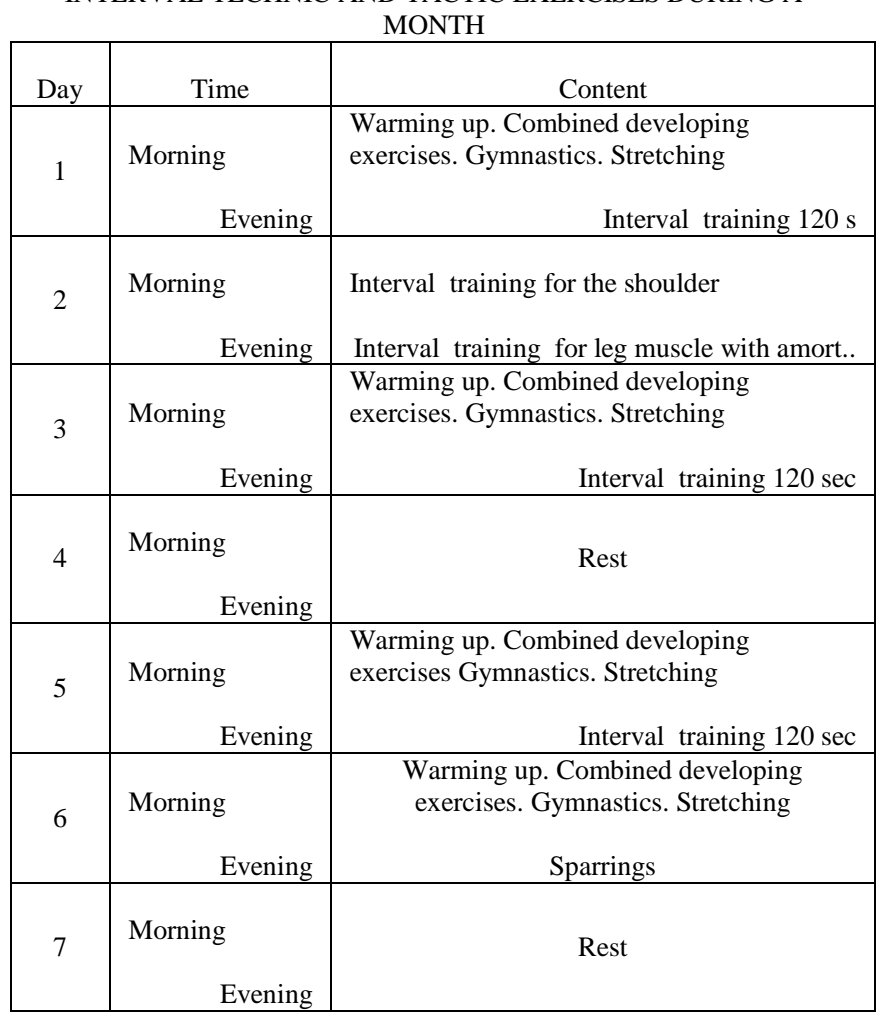

The second group -10 athletes 19-22 years old ,divided into 5 pairs - numbers 1-2 . Length of training lessons with this kind of sport - 8,9 $\pm 1,4$ years, qualification candidate master -master of sports. Purpose of the research Given group of athletes did tactics and special exercises by means of interval method totally equipped according to the competition policy in pairs, however the period of one exercise was no more than $8 \mathrm{sec}$. In pairs number 2 holds hooking pads at the body level and number 1 strikes from the place with both legs with maximum seed of strike doliochagi as the mostly spread strike in taekwondo to hooking pads in the time interval up to $8 \mathrm{sec}$., while time-out speed of strikes is decreases. Next the athletes was given the following task: number 2 makes attacks with the strikes dolio-chagi to the head and body in any sequence and any combination, number 1 is defended by distance, blocks, arms, cover-ups, drops away, going aside from the attack line. Any variants of tasks can be worked out. This task for number 2 is less energy consuming and speeds the process of restoring for number 1.There were made 5 spurts in one series, then number 2 made the same task, while number 1 held the hooking pads. Time of active recovery of number 1is 1 minute. There were planed three trainings in the week's microcycle: the first, third and the fifth days. In total there were made 5 series. The content of the microcycle is represented in table II.

TABLE II. MICROCYCLE OF TRAINING BASED ON MAKING INTERVAL SPURT EXERCISES DURING A MONTH

\begin{tabular}{|c|c|c|}
\hline Day & Time & Content \\
\hline 1 & $\begin{array}{l}\text { Morning } \\
\text { Evening } \\
\end{array}$ & $\begin{array}{l}\text { Warming up. Combined developing exercises. } \\
\text { Gymnastics. Stretching } \\
\text { Interval spurt training for legs }\end{array}$ \\
\hline 2 & $\begin{array}{l}\text { Morning } \\
\text { Evening }\end{array}$ & $\begin{array}{l}\text { Interval trainings for the shoulder } \\
\text { Interval trainings for legs muscles with } \\
\text { amortisation }\end{array}$ \\
\hline 3 & $\begin{array}{l}\text { Morning } \\
\text { Evening }\end{array}$ & $\begin{array}{l}\text { Warming up. Combined developing exercises. } \\
\text { Gymnastics. Stretching } \\
\text { Interval spurt training for legs }\end{array}$ \\
\hline 4 & $\begin{array}{l}\text { Morning } \\
\text { Evening }\end{array}$ & Rest \\
\hline 5 & $\begin{array}{l}\text { Morning } \\
\text { Evening }\end{array}$ & $\begin{array}{l}\text { Warming up. Combined developing exercises. } \\
\text { Gymnastics. Stretching } \\
\text { Interval spurt training for legs }\end{array}$ \\
\hline 6 & $\begin{array}{l}\text { Morning } \\
\text { Evening }\end{array}$ & $\begin{array}{l}\text { Warming up. Combined developing exercises. } \\
\text { Gymnastics. Stretching } \\
\text { Sparrings } \\
\end{array}$ \\
\hline 7 & $\begin{array}{l}\text { Morning } \\
\text { Evening }\end{array}$ & Rest \\
\hline
\end{tabular}

Before the beginning and after the end of the experiment all the athletes went through the test in the terms of laboratory doing the test with the gradually increasing load on ergometric bicycle Ergoline-Ergoselect 200-K. Prime power $38 \mathrm{VT}$, incremental step $38 \mathrm{VT}$, load duration $2 \mathrm{~min}$., frequency of cycling $75 \mathrm{~min}$. At the same time they fixed 
the oxygen consumption excess of $\mathrm{CO} 2$ with the help of gas sensor Metalyzer 3B_R2 (Cortex, Germany).Heart rate registration was held with the help of heart rate measurement system Polar team system 2. After the end of the test Maximum Anaerobic Performance (MAM) was defined at doing short spurt with the maximum intensity during 5-6 sec. on ergometric bicycle Monark 894 Peak Bike. External load rate was set on the basis of index of $0.09 \mathrm{x}$ athlete's body weight. Before the beginning of every training lesson, as well as after the end of the first and second round series at the $1^{\text {st }}$ and $3 \mathrm{~d}$ minutes of recovery capillary blood draw was taken in order to define lactate concentration with the help of hand-held device Lactate Scout + . While doing the exercises and in the period of recovery heart rate registration was held for every athlete with the help of team system Polar team system 2 pro with discreetness of record of $5 \mathrm{sec}$. Before the beginning of pedagogical experiment there were no true differences between athletes according to the level of fitness (Table 3 ).

TABLE III. PHYSICAL FITNESS PROFILE OF TAEKWONDO ATHLETES OF HIGH QUALIFICATION TRAINING ACCORDING TO DIFFERENT METHODS OF TRAINING PROCEDURE UP TO EXPERIMENT

\begin{tabular}{|c|c|c|c|c|c|c|c|}
\hline \multirow[t]{2}{*}{ Data } & \multicolumn{3}{|c|}{$\begin{array}{l}\text { Experimental group } \\
\text { 1(EG1) before the } \\
\text { experiment }\end{array}$} & \multirow[t]{2}{*}{$\mathrm{p}$} & \multicolumn{3}{|c|}{$\begin{array}{l}\text { Experimental group } \\
\text { 2(EG2) before the } \\
\text { experiment }\end{array}$} \\
\hline & $\mathrm{X}$ & \pm & $\sigma$ & & $X$ & \pm & $\sigma$ \\
\hline $\begin{array}{l}\text { Body } \\
\text { weight, } \mathrm{kg}\end{array}$ & 67,6 & \pm & 4,9 & $\begin{array}{c}> \\
0,1\end{array}$ & 67,9 & \pm & 3,8 \\
\hline $\begin{array}{l}\text { Heart rate } \\
\text { Aerobic } \\
\text { limen, beat }\end{array}$ & 149 & \pm & 4,2 & $\begin{array}{c}< \\
0,0 \\
01\end{array}$ & 131 & \pm & 5,6 \\
\hline $\begin{array}{l}\text { Aerobic } \\
\text { limen, } \mathrm{ml} / \mathrm{kg}\end{array}$ & 19 & \pm & 4,9 & $\begin{array}{l}> \\
0,1\end{array}$ & 21 & \pm & 4,5 \\
\hline $\begin{array}{l}\text { Heart rate } \\
\text { Anaerobic } \\
\text { limen, beat }\end{array}$ & 165 & \pm & 3,7 & $\begin{array}{c}> \\
0,1\end{array}$ & 161 & \pm & 6,1 \\
\hline $\begin{array}{l}\text { Anaerobic } \\
\text { limen, } \mathrm{ml} / \mathrm{kg}\end{array}$ & 32 & \pm & 3,1 & $\begin{array}{c}> \\
0,1\end{array}$ & 34 & \pm & 5,4 \\
\hline MAM, Vt/kg & 11,6 & \pm & 0,9 & $\overrightarrow{0_{1}}$ & 11,9 & \pm & 0,4 \\
\hline
\end{tabular}

\section{RESULTS}

The results of 2 kinds of tactic and special interval exercises of different duration $120 \mathrm{sec}\left(\mathrm{EG}_{1}\right)$ and up to 8 $\sec \left(E_{2}\right)$ showed that after the first series of exercises it is marked:

Significant difference of initial heart rate $(\mathrm{p}<0,05)$ before the next series of exercises which was higher while doing short (up to $8 \mathrm{sec}$.) exercises.

Absence of true differences of middle and maximum datum of heart rate $(p>0,5)$.

True differences of heart rate $(p<0,05)$ and concentration of lactate $(\mathrm{p}<0,001)$ at the first and third min. of recovery which were higher after the end of short (up to 8 sec) exercises (Table IV).

After the final series of exercises it is marked:

True difference of heart rate $(\mathrm{p}<0,05)$, which was higher at training short exercises (up to $8 \mathrm{sec}$ ).
- Absence of true differences of middle and
maximum meanings of heart rate in the main part of training lessons and period of recovery at the first and third min $(\mathrm{p}>0,5)$.

True differences of lactate concentration $(p<0,001)$ only at the third min of recovery which were significantly higher after the end of short (up to $8 \mathrm{sec}$ ) exercises (Table V).

TABLE IV. DATUM OF HEART RATE AND LACTATE CONCENTRATION OF TAEKWONDO ATHLETES OF HIGH QUALIFICATION AFTER THE FIRST SERIES OF TACTIC AND SPECIAL EXERCISES OF DIFFERENT DURATION.

\begin{tabular}{|c|c|c|c|c|c|c|c|}
\hline \multirow[t]{3}{*}{ Datum } & \multicolumn{7}{|c|}{ After the first series } \\
\hline & \multicolumn{4}{|c|}{ EG1 } & \multicolumn{3}{|c|}{ EG2 } \\
\hline & $\mathrm{X}$ & \pm & $\sigma$ & $\mathrm{p}$ & $\mathrm{X}$ & \pm & $\sigma$ \\
\hline Heart rate before, beat/min & 103 & \pm & 5,0 & $<0,05$ & 110 & \pm & 6,8 \\
\hline La original, $\mathrm{MM} / 1$ & 1,4 & \pm & 0,3 & $>0,5$ & 1,4 & \pm & 0,2 \\
\hline Heart rate average, beat $/ \mathrm{min}$ & 161 & \pm & 1,6 & $>0,5$ & 163 & \pm & 7,8 \\
\hline Heart rate $\max$, beat $/ \mathrm{min}$ & 181 & \pm & 1,3 & $>0,1$ & 183 & \pm & 5,1 \\
\hline Heart rate $1 \mathrm{~min}$ recovery & 136 & \pm & 9,5 & $<0,05$ & 144 & \pm & 4,5 \\
\hline La 1 min recovery, $\mathrm{MM} / 1$ & 6,0 & \pm & 2,4 & $<0,001$ & 16,8 & \pm & 2,3 \\
\hline Heart rate $3 \mathrm{~min}$. recovery & 110 & \pm & 8,5 & $<0,001$ & 126 & \pm & 5,7 \\
\hline La 3 min recovery, $\mathrm{MM} / 1$ & 4,5 & \pm & 2,8 & $<0,001$ & 11,1 & \pm & 1,6 \\
\hline
\end{tabular}

TABLE V. DATUM OF HEART RATE AND LACTATE CONCENTRATE OF TAEKWONDO ATHLETES OF HIGH QUALIFICATION AFTER THE FINAL SERIES OF TACTIC AND SPECIAL EXERCISES OF DIFFERENT DURATION.

\begin{tabular}{|c|c|c|c|c|c|c|c|}
\hline \multirow{3}{*}{ Datum } & \multicolumn{7}{|c|}{ After the final series } \\
\hline & \multicolumn{3}{|c|}{$\mathrm{EG}_{1}$} & & \multicolumn{3}{|c|}{$\mathrm{EG}_{2}$} \\
\hline & $\mathrm{X}$ & \pm & $\sigma$ & $\mathrm{p}$ & $\mathrm{X}$ & \pm & $\sigma$ \\
\hline $\begin{array}{l}\text { Heart rate before, } \\
\text { beat } / \mathrm{min}\end{array}$ & $\begin{array}{c}10 \\
2\end{array}$ & \pm & 1,7 & $\begin{array}{c}< \\
0,001\end{array}$ & 118 & \pm & 7,1 \\
\hline $\begin{array}{l}\text { Heart rate average, } \\
\text { beat } / \mathrm{min}\end{array}$ & $\begin{array}{c}16 \\
3\end{array}$ & \pm & 2,8 & $>0,5$ & 163 & \pm & 4,2 \\
\hline $\begin{array}{l}\text { Heart rate } \max \\
\text { beat/min }\end{array}$ & $\begin{array}{c}18 \\
7\end{array}$ & \pm & 5,9 & $>0,5$ & 184 & \pm & 7,6 \\
\hline $\begin{array}{l}\text { Heart rate } 1 \mathrm{~min} \\
\text { recovery }\end{array}$ & $\begin{array}{c}14 \\
4\end{array}$ & \pm & 4,8 & $>0,5$ & 141 & \pm & 7,1 \\
\hline $\begin{array}{l}\mathrm{La} 1 \mathrm{~min} \text { recovery, } \\
\mathrm{MM} / \mathrm{l}\end{array}$ & $\begin{array}{c}11 \\
7\end{array}$ & \pm & 5,5 & $>0,5$ & 12,8 & \pm & 4,3 \\
\hline $\begin{array}{l}\text { Heart rate } 3 \mathrm{~min} \text {. } \\
\text { recovery }\end{array}$ & $\begin{array}{c}11 \\
4\end{array}$ & \pm & 4,4 & $>0,5$ & 115 & \pm & 2,1 \\
\hline $\begin{array}{l}\text { La } 3 \text { min recovery, } \\
\mathrm{MM} / 1\end{array}$ & 5,5 & \pm & 1,5 & $\begin{array}{c}< \\
0,001\end{array}$ & 9,1 & \pm & 1,6 \\
\hline
\end{tabular}

Thus, true differences between two kinds of trainings after the end of the first and final series refer to the lactate concentration and heart rate in the period of recovery which are significantly lower while doing the exercises no more than $120 \mathrm{sec}$. Doing tactic and special exercises with the help of interval method with the average time scale (120 c) with the intensive time scale comparing with short (up to 8 sec) exercises leads to quicker recovery of muscular system. After the end of four days mesocycle of training 
repeated examination of athletes was revealed in order to define the changes at stage of physical fitness of athletes

After the end of pedagogical experiment of athletes doing tactics and special exercises $u$ to 8 seconds true differences were revealed by the level of speed-power opportunities $(p>0,1)$. On the contrary in the group of athletes doing tactic and special exercises $120 \mathrm{sec}$ with the average intensity there was a true growth of aerobic opportunities, oxygen consumption at the level of aerobic limen. There are true differences between athletes only at maximum alactic $(\mathrm{p}<0,001)$. The results of the research are represented in the table 6 .

TABLE VI. PHYSICAL FITNESS PROFILE OF ATHLETES OF STRIKING KINDS OF BATTLES TRAINING AT DIFFERENT METHODS AFTER THE EXPERIMENT

\begin{tabular}{|c|c|c|c|c|c|c|c|}
\hline \multirow{2}{*}{ Data } & \multicolumn{3}{|c|}{$\begin{array}{c}\text { EG1 after the } \\
\text { experiment }\end{array}$} & \multirow{2}{*}{$\mathrm{p}$} & \multicolumn{3}{|c|}{$\begin{array}{l}\text { EG1 the } \\
\text { experiment }\end{array}$} \\
\hline & $\mathrm{x}$ & \pm & $\sigma$ & & $\mathrm{x}$ & \pm & $\sigma$ \\
\hline Body weight, kg & 67,4 & \pm & 4,6 & $>0,1$ & 67,2 & \pm & 4,4 \\
\hline $\begin{array}{l}\text { Heart rate Aerobic } \\
\text { limen, beat }\end{array}$ & 137 & \pm & 2,8 & $\begin{array}{c}< \\
0,05\end{array}$ & 130 & \pm & 7,2 \\
\hline Aerobic limen, $\mathrm{ml} / \mathrm{kg}$ & 23 & \pm & 3,7 & $>0,1$ & 22 & \pm & 4,0 \\
\hline $\begin{array}{l}\text { Heart rate Anaerobic } \\
\text { limen, beat }\end{array}$ & 162 & \pm & 6,2 & $>0,1$ & 160 & \pm & 5,6 \\
\hline Anaerobic limen, $\mathrm{ml} / \mathrm{kg}$ & 39 & \pm & 6,9 & $>0,1$ & 35 & \pm & 5,5 \\
\hline MAM, vt/kg & 11,4 & \pm & 0,9 & $\begin{array}{c}< \\
0,00 \\
1\end{array}$ & 13,6 & \pm & 0,2 \\
\hline
\end{tabular}

Planning of the stage of immediate athletes fitness to the start using tactic and special short exercises (up to $8 \mathrm{sec}$ ) leads to the growth of only speed-power opportunities of muscles, while at the increase of exercises duration (120 sec) and decrease of intensity there is a growth of aerobic opportunities of muscles.

Choice of duration of tactic and special exercise depends on the task solving at the stage of immediate run-up to start and currant level of physical fitness of athletes, limiting factors.

\section{DISCUSSION}

Given results of findings et us to define 2 main ways of training tactic and special exercises which can be applied by the athletes at the stage of immediate run $u$ to the start.

While planning the mesocycle of training athletes of striking kinds of battles the aim of which is the increase of aerobic opportunities it is necessary to do 2 training lessons with intervals of tactic and special exercises $u$ to $120 \mathrm{sec}$ and one training lesson with short interval tactic and special exercises (up to $8 \mathrm{sec}$ ).

While planning mesocycle of training athletes of striking kinds of battles which aim is the increase of speed and power opportunities of two training lessons with short interval tactic and special lessons (up to $8 \mathrm{sec}$ ) and one training lesson with short interval tactic and special exercises up to $120 \mathrm{sec}$.

\section{CONCLUSION}

1. Experimental approbation of interval tactic and special exercises with the length of $120 \mathrm{sec}$. at the precontest stage leads to the increase of aerobic opportunities of muscles. $(\mathrm{p}<0,05)$.

2. Experimental approbation of interval tactic and special exercises with the length of $8 \mathrm{sec}$. at the precontest stage leads to the growth of only speed and power of opportunities of muscles $(\mathrm{p}<0,05)$.

3. Choice of duration of tactic and special exercises depends on the tasks solved at different stages of annual cycle and current level of different parts of physical fitness of taekwondo athletes.

\section{References}

[1] Akopyan A.O. Interconaction of physical and technic and tactic fitness of young qualified boxers of the age of 15-16 years old. Sport Science Newsletter. 2014, 1, pp. 24-27.

[2] Bleer A.N. Athelete's physical fatigue influence on safety of performance of movement skill of a wrestle. Theory and practice of physical culture: coach: magazine in magazine. 2000, 6, pp. 36.

[3] Viidy V.A. Upbringing of local power and muscle endurance of upper extremity of sambo wrestlers. Candidate's thesis. M. 2009, 23.

[4] Dvoichenko V.V. Planning of special physical training of highly qualified taekwondo female athletes at precontest stage. Candidate's thesis. M. 2014, 22.

[5] Eliseev S.V. Precontest training of sambo wrestlers of high qualification. Candidate's thesis. M. 2001, 24.

[6] Isaev A.P. Loco-regional conditioning in the system of training and adaptation of runners and racing-skiers in the conditions of plain and middle altitude: monogaphy. Chelyabinsk: Publishing Center South Ural State University. 2014, 286.

[7] Maksimov D.V. Physical training of combats (sambo and judo). Theory and practice recommendations. TVT Devision. 2011, 160.

[8] Myakinchenko E.B. Development of local conditioning in cyclic kind of sport. M. TVT Devision. 2017, 338.

[9] Pashintsev V.G. Speed power development of glycolytic endurance in judo. Theory and practice of physical culture. 2015, 3, pp. 20-22.

[10] Svishev, I.D. Speed of blood circulation in extremity of arms and legs as a limiting factor of local endurance of wrestlers. Russian State University of physical culture, sport, youth and tourism (SCOLIPE), Department of theory and methodology of combats. M. 2012, 3, pp. 918.

[11] Seluyanov V.N. Footballers' physical training. M. TVT Devision. 2006, 191.

[12] Butios, S. Changes in heart rate and blood lactate concentration as intensity parameters during simulated Taekwondo competition. The Journal of sports medicine and physical fitness. 2007, 47(2), pp. 179185.

[13] Alexsandr S. Kuznetsov. Russian Professor's meeting. Russian Journal of Physical Education and Sport. 2019, 14(1), pp. 17-22. DOI: 10.14526/2070-4798-2019-14-1-18-24

[14] Casolino, E. Physiological vs psychological evaluation in taekwondo elite athletes. International journal of sports physiology and performance. $2012,7(4)$, pp. 322-331. 